Nicolás Sánchez-

\section{Albornoz. Cárceles}

\section{$y$ exilios. Barcelona:}

\section{Anagrama, 2012,}

\section{5p.}

\section{Mariela P. Sánchez}

Instituto de Investigaciones en

Humanidades y Ciencias Sociales (UNLPCONICET)- Facultad de Humanidades

y Ciencias de la Educación - Universidad

Nacional de La Plata - Argentina.

Doctora en Letras por la Universidad

Nacional de La Plata, y Profesora y

Licenciada en Letras por la Universidad

de Buenos Aires. Se desempeña como

docente en la Facultad de Humanidades

y Ciencias de la Educación de la UNLP.

Es becaria postdoctoral del Consejo

Nacional de Investigaciones Científicas y

Técnicas; su lugar de trabajo es el Instituto

de Investigaciones en Humanidades y Ciencias Sociales (UNLP/CONICET).

Integra el proyecto de investigación

"Diálogos transatlánticos. Estudio de las relaciones en el campo de la cultura y las letras entre Argentina y España” (Agencia Nacional de Promoción Científica y Tecnológica y Programa de Incentivos UNLP), bajo la dirección de la Dra. Raquel Macciuci, y el proyecto "Memorias en segundo grado: Posmemoria de la guerra civil y el franquismo en la España del siglo XXI" (2013LINE-01, Bco. Santander y Universitat Rovira i Virgili). Participó como profesional de apoyo en el proyecto internacional de investigación "Guerra Civil y exilio republicano español en la Argentina", del Ministerio de Cultura de España en colaboración con la Fundación "Claudio Sánchez-Albornoz", bajo la dirección de la Dra. María Teresa Pochat. Ha presentado diversos trabajos relacionados con sus temas de investigación en publicaciones académicas y reuniones científicas.

Contacto: maripausanchez@yahoo.com.ar 
La propuesta de cubrir cuatro décadas signadas por la extensa dictadura franquista y por las consecuencias que esto tuvo para Nicolás Sánchez-Albornoz a través de etapas de privación de la libertad y de diásporas presenta en Cárceles y exilios una cuidada administración de documentos y análisis.

El autor enuncia y organiza sus vivencias, y echa luz sobre las condiciones a las que estuvo expuesta una generación que vio coartados sus derechos, tanto en lo relativo a libertades individuales como a su cada vez más exigua posibilidad de desarrollo en el ámbito de la universidad. El hecho de que el recorrido histórico esté focalizado en la experiencia que atañe a un determinado grupo etario y que se centre en sus encierros y desplazamientos no implica que se soslaye la contemplación de otras franjas generacionales: la frecuente alusión a la figura de Claudio Sánchez-Albornoz, padre del autor, sirve de contrapunto para un relevamiento de los variados pero a la vez convergentes impactos que ha tenido el franquismo en sujetos de todas las edades. La temática familiar, no introducida para volcar un anecdotario personal, ilumina un espectro de problemáticas donde abuelos, hijos y nietos deben desarrollar estrategias para seguir adelante con la educación, la vida cotidiana y la vida laboral dentro de las normas -o mejor, dentro de las irregularidades- dictadas por el régimen impuesto. En este sentido, resulta clarificador el hincapié en las fases de adaptación y puesta al día demandadas por los cambios de sistema educativo y aún de lengua vehicular sobrellevados por los niños. Si bien la infancia es anterior a los dos ejes del título, ya que no hay aún, obviamente, cárceles ni exilios, su evocación es más que pertinente para la contextualización del carácter cada vez más riesgoso de las consecuencias deparadas por el régimen.

El libro ofrece una pormenorizada descripción de episodios centrales para comprender diversos planos de una compleja realidad de posguerra y dictadura. La gestación, el fortalecimiento y la continuidad de vínculos e imbricaciones político-universitarias están abordados a través de los avatares que transitaron los estudiantes y los jóvenes graduados durante el 
franquismo. En este punto, el acceso a la educación pública en Argentina ocupa un lugar de especial tratamiento.

Las instancias paratextuales contribuyen en Cárceles y exilios a una complementación que amplía e ilustra lo planteado en el cuerpo del texto en primera persona singular. El espacio de las notas al pie brinda en ocasiones el sustento documental que da cuenta de los hechos evocados previamente desde la experiencia individual e introduce al mismo tiempo otras voces u otros títulos a los que acudir a los fines de cotejo o profundización. Las páginas enceradas que se destina a una sucesión de imágenes, entre fotografías, dibujos y reproducciones de fuentes, redoblan la apuesta del prolijo avance cronológico y se destacan como un relieve que torna más vívidas algunas anécdotas y algunos nombres. Los dibujos realizados por otros compañeros en prisión y a posteriori, y la identificación de cada uno de ellos aumentan la intensidad de los temas tratados y permiten un asomo mayor del lector a escenas de gran densidad histórica. Lo mismo ocurre, por ejemplo, con la fotografía de las chabolas improvisadas en terrenos aledaños a Cuelgamuros, que imprimen una fuerza irreemplazable en lo relativo a la desolación y la desesperanza frente a los abusos allí cometidos. Por otra parte, los pasaportes y los trabajosos y curiosos inconvenientes interpuestos para su obtención dan cuenta de diferentes coyunturas internacionales y, por momentos, del accionar de figuras protagónicas del republicanismo español en el exilio.

Algunos acontecimientos narrados están por primera vez volcados en un libro; otros, como los que atañen a las prisiones, son pasibles de entrar en diálogo con acercamientos anteriores en algún otro soporte, por ejemplo el episodio de la huida de Cuelgamuros junto con Manuel Lamana, algo determinante ya que fue lo que permitió pasar a Francia y luego a América. Sánchez-Albornoz, con mención explícita y algo detenida de la película en la que se cuenta y hasta cierto punto se estiliza ese episodio, prefiere no abundar $y$, sin desestimar su centralidad, lo incorpora en un 
devenir que precisa de otros eslabones de alguna manera esenciales. La elección de una determinada denominación del sitio en cuestión supone un posicionamiento ético y una justificada relectura de la historia.

Los posibles efectos emocionales de las noticias más impactantes, como la de la propia condena, se disuelven en decisiones sobre el modo de escritura que ofrecen claridad y a la vez una apertura a la contemplación de un padecimiento colectivo. Claro ejemplo de esto es la interposición de un cuadro comparativo que grafica la condena aplicada a cada uno de los compañeros apresados por una causa afín, por cuestiones de militancia universitaria. Dicho cuadro muestra en tres columnas el nombre de cada afectado, la pena pedida por el fiscal y la que fue finalmente aplicada, que supera significativamente la que había sido requerida. La disposición visual de nombres y datos dan margen al lector para que haga su propia hipótesis de lectura, para que lea y revise aquello bajo lo que subyace una complejidad tanto en términos jurídicos como en el terreno privado, dando lugar a una amplia gama de preguntas en torno a los silencios encarnados por cifras con las que el franquismo postergó y en algunos casos aniquiló cualquier atisbo de desarrollo personal o profesional.

Un tono que evita cualquier tipo de emotividad exacerbada sostiene el relato preservándolo de excesos capaces de solapar la fuerza de lo que significa el paso por diferentes centros de detención, con lo que acarrea en materia de desarrollo de tácticas, actuación clandestina, camaradería, supervivencia y percepción de la realidad circundante. Este recurso estaría amparado en la conclusión y la lejanía de las consecuencias más directas de los sucesos narrados, pero también en el reconocimiento de ciertas características que hicieron del encierro de Nicolás Sánchez-Albornoz algo más llevadero que lo ocurrido a otras víctimas de la dictadura franquista. Dicha modalidad en la presentación de los hechos da lugar a ciertas brechas que, pese a lo nefasto de este período de la historia española reciente, permiten que se cuelen guiños o toques de ironía y, a 
veces, hasta una derivación sutilmente humorística.

La materia evocada se halla contenida por un encuadre que subraya el aludido tono de distanciamiento acentuado por un matiz profesional claro, que denota constantemente al historiador detrás del autor que revela su "yo". Subyace siempre la idea de una pervivencia de los efectos de un conflicto bélico que no finalizó de modo tajante a partir de los límites temporales dictados por el bando sublevado frente a un gobierno legalmente electo. Esta circunstancia ya había sido tratada por el autor en el artículo "La liquidación de la Guerra Civil", que abre el número monográfico de la revista argentina Olivar dedicado en 2006 a la memoria de la contienda. Allí se hacía necesaria una modalidad más punzante; la mirada sobre los padecimientos estaba focalizada en diferentes áreas afectadas por el accionar franquista que el autor observaba y analizaba crítica e incisivamente. En esta ocasión, aunque la obra constituiría una expresión de las llamadas "escrituras del yo", la puesta en juego de una indignación o de un apasionamiento es inversamente proporcional a la cercanía de la experiencia transmitida. La austeridad deja entrever un trabajo de archivo que en más de una oportunidad ha debido lidiar, en fecha no demasiado lejana a la publicación del libro, con una dificultad de acceso a aquello que durante tantas décadas estuvo vedado y que se torna material de consulta y de sostén insoslayable ante el investigador, quien no deja de ser un profesional a pesar de estar manejando una materia tan sensible y tan propia. No obstante, el texto deviene accesible y significativo no sólo para historiadores, sino también para todo interesado en aspectos político-sociales relativos a períodos dictatoriales y, obviamente, para los interesados y estudiosos de la dictadura franquista. Pero el alcance geográfico supera ampliamente los límites peninsulares para dar cabida a las distintas fases y latitudes de cada uno de los exilios. El título sintetiza de manera contundente y dramática, sin desplazar la sobriedad, una serie de corolarios que tienen como denominador común la arbitrariedad de quienes dispusieron de los proyectos, 
el crecimiento y la formación de muchísimos españoles. El plural del título contiene, por una parte, la sucesión de lugares de la reclusión sufrida por el autor y los diferentes destinos de destierro. En el primer término, se encierra escuetamente lo que demandará un detenido desarrollo en los capítulos correspondientes a cada una de las cuatro prisiones. El relato de las cárceles se abre con la detención en Barcelona y la permanencia en la Puerta del Sol, con lo que esto supuso en cuanto a incertidumbre sobre el destino siguiente y al hecho de ser testigo auditivo de la aplicación de torturas. La dura trayectoria continúa en Alcalá de Henares, Carabanchel y Cuelgamuros, con las particularidades de cada uno de estos sitios y sobre la base de un abordaje específico que justifica tanto las elecciones terminológicas como la selección de los episodios más destacados.

El título concentra además, en el segundo núcleo que lo constituye, la singularidad que suponen Francia, Argentina y Estados Unidos como objetivos mediante los cuales se tornó necesario para el autor guardar distancia de la España franquista con diferentes niveles de premura, destinos en los que debió seguir adelante, reiniciando incluso, en una de esas ocasiones, los estudios, ante la falta de homologación de los contenidos ya evaluados en España.

Las opiniones sobre la etapa argentina merecerán en los lectores de aquel país una especial atención y es altamente probable que despierten desde ocasionales diferencias hasta los más abiertos desacuerdos, principalmente en lo que hace al tratamiento de procesos locales de gran complejidad; pero esto, lejos de suponer una digresión, agrega capas discursivas que trascienden el mero relato. Ciertas apreciaciones acerca del peronismo -que recuerdan, en algunos aspectos, la mirada de María Teresa León en Memoria de la melancolía-, entre otros detenimientos puntuales en períodos históricos argentinos, albergan en potencia una discusión que podría extenderse mucho más allá de las páginas del libro. Sin embargo, acaso esos pasajes que escapan a la cobertura más específica de la vida del exiliado en 
lo que hace a su experiencia de cárceles y exilios, y migran hacia la interpretación -y hacia una mirada que intenta ser descriptiva pero que echa mano de puntos de vista muy marcados- otorgan vías de ingreso a una lectura más activa. Dichas zonas textuales pueden funcionar, incluso, como una invitación al diálogo o al debate, puesto que es un tema no agotado sino presente.

Uno de los capítulos está dedicado a la gestación de la editorial Ruedo Ibérico. Los elementos allí contemplados, desde la consideración de la imprescindible figura de José Martínez hasta los aspectos anecdóticos que hacen al recuerdo de los esfuerzos compartidos, conforman un abordaje insoslayable para el estudioso de la industria editorial y para los interesados en la importancia y el derrotero de las publicaciones de carácter periódico derivadas de esa gestación, como Galicia Hoy.

En Cárceles y exilios, la argumentación le gana a lo expositivo y se mueve entre lo susceptible de ser documentado y una muy calibrada subjetividad, en una mesurada administración de esos recursos. Finalmente, este libro no sólo nos convoca a profundizar el conocimiento de las cárceles y los exilios de Nicolás Sánchez-Albornoz. La mentada elección del plural del título se complementa con el acercamiento a las historias de otros protagonistas contemporáneos, tanto compañeros como antecesores que apoyaron o dieron la espalda a los jóvenes. Resultan sumamente interesantes y agudas las observaciones del autor sobre estos últimos. Estos factores alejan, de forma coherente con el enfoque adoptado en los diferentes capítulos, todo riesgo de autorreferencialidad absoluta para dar paso a que el lector se interese, asimismo, por otras cárceles y por otros exilios. 